\title{
EL PRINCIPIO DE IMPARCIALIDAD EN LA JUSTICIA PENAL MILITAR COLOMBIANA
}

\author{
Ingrid Regina Petro González ${ }^{1}$
}

\section{Resumen}

La Constitución Política reconoce la existencia de jurisdicciones de carácter especial. Entre ellas la justicia penal militar colombiana, entendida como aquella que se encarga de la investigación y juzgamiento de delitos cometidos por los miembros de la fuerza pública en servicio activo y en relación con el mismo (Chaparro, 2010). Los órganos adscritos a la justicia penal militar colombiana, no pertenecen a la rama judicial, sino a la rama ejecutiva del poder público, pues dependen del Ministerio de Defensa Nacional, Dirección Ejecutiva de la Justicia Penal Militar y su regulación constitucional se encuentra en el Capítulo VII Título 7. La justicia penal militar en Colombia, está regulada por disposiciones de naturaleza jurídica diversa, en ciertas ocasiones por decretos expedidos por el ejecutivo con fuerza de ley y en otras por leyes de la República. En la actualidad, esta jurisdicción encuentra su sustento normativo en las Leyes 522 de 1999 que en una misma norma se ocupa de la parte sustantiva y procedimental, y la Ley 1407 de 2010 la cual se encuentra vigente en su parte sustantiva, ya que hasta ahora no se ha implementado el Sistema Acusatorio para el Juzgamiento de los miembros de la fuerza pública, encontrándose además con la Ley 1765 de 2015 la cual reestructura la justicia penal militar y policial y se establecen requisitos para e desempeño de cargos al interior de la misma jurisdicción.

Fundamentos normativos que ayudarán para que por parte de los operadores jurídicos se garantice el principio de imparcialidad al interior de la misma jurisdicción al momento de impartir justicia para los miembros de la fuerza pública.

Palabras Clave: el principio de imparcialidad, justicia penal militar, jurisdicción y fuerza pública.

${ }^{1}$ Abogada, Candidata a Doctora, Magister en Derecho Procesal, Especialista en Derecho Administrativo y Derecho Procesal Contemporáneo, Docente Investigadora de la Facultad de Derecho y Coordinadora de la Especialización en Derecho Procesal, Probatorio y Oralidad de la Universidad Libre Seccional Pereira, email: irpetro@unilibrepereira.edu.co , ingridreginapetro@hotmail.com 


\title{
Ingrid Regina Petro González
}

\begin{abstract}
The Constitution recognizes the existence of special jurisdictions. These include the Colombian military criminal justice system, understood as that which is responsible for the investigation and prosecution of crimes committed by members of the security forces on active duty and in connection with it (CP. 2010, p. 98). The bodies attached to the Colombian military criminal justice system do not belong to the judicial branch, but to the executive branch of public power, since they depend on the Ministry of National Defence, the Executive Directorate of Military Criminal Justice, and their constitutional regulation is found in Chapter VII, Title 7. Military criminal justice in Colombia is regulated by provisions of a diverse legal nature, on certain occasions by decrees issued by the executive with the force of law and on others by laws of the Republic. At present, this jurisdiction finds its normative support in Laws 522 of 1999, which deals with the substantive and procedural part of the same law, and Law 1407 of 2010, which is in force in its substantive part, since until now the Accusatory System for the Judgement of members of the public force has not been implemented, as well as Law 1765 of 2015, which restructures the military and police criminal justice system and establishes requirements for the performance of positions within the same jurisdiction.
\end{abstract}

Regulatory foundations that will help ensure that legal operators guarantee the principle of impartiality within the same jurisdiction when providing justice for members of the security forces.

Keywords: the principle of impartiality, military criminal justice, jurisdiction and public force.

on la promulgación de la Constitución Política de 1991, se indica
la necesidad que Colombia tenga para su defensa unas fuerzas
militares y un cuerpo de policía permanente con el objetivo primordial de defender la soberanía nacional, la independencia, la integridad del territorio, el orden constitucional, por un lado; y de garantizar a los residentes en Colombia el libre ejercicio de los derechos y garantías consagrados en la misma Carta, por el otro (Petro Gónzalez, Henao Toro, \& Marín Pinto, 2013).

De ahí la existencia de una Fuerza pública, la cual cuenta con la organización de una Jurisdicción, conocida como Justicia Penal Militar Colombiana, encargada de la investigación y juzgamiento de los delitos co- 
metidos por los miembros de dicha fuerza pública en servicio activo y en relación con el mismo servicio; como lo señala el artículo 221 de la Constitución Política, el cual atribuye esta competencia a las Cortes Marciales y Tribunales Militares con arreglo a las prescripciones de una Ley Penal Militar (Ley 522, 1999).

Se pretende estudiar la justicia como parte fundamental del derecho, así como los principios tomados desde la teoría de Robert Alexy; para cumplir el objetivo general y establecer el alcance de los principios de imparcialidad e independencia al interior de la Justicia Penal Militar en Colombia, el cual genera cuestionamiento por parte de los operadores judiciales al administrar justicia como función pública del derecho.

Por otra parte, la estructura del proceso penal militar colombiano de conformidad con las leyes 522 de 1999, 1407 de 2010 y 1765 de 2015 se debe analizar con la finalidad de indicar la conveniencia en la aplicación procedimental; y el cumplimiento de los principios de imparcialidad e independencia en la justicia penal militar con el fin de explorar la relación de los jueces penales militares. Por ultimo explicar la necesidad de una jurisdicción penal militar adscrita a la rama judicial del poder público colombiano. Ante lo cual se ha formulado la siguiente pregunta problema ¿Cuál ha sido el alcance de los principios de Imparcialidad e Independencia al interior de la justicia penal militar en Colombia?

La presente investigación tendrá una tendencia iuspositivista partiendo de la teoría sobre la justicia de H.L.A. Hart., quien manifiesta que se debe distinguir entre reglas primaria de obligación y reglas secundarias de reconocimiento, son tantos los actos distintivos del derecho y tantas las ideas de la estructura del pensamiento jurídico que requieren su elucidación a uno o a ambos tipos de reglas, que pueden ser consideradas como la esencia del derecho (Hart, 1992) .

\section{Metodología}

El paradigma que se tendrá para la realización de la investigación es Teórica-Analítica utilizando un enfoque cualitativo por cuanto del problema planteado, se establecerá el alcance del principio de imparcialidad e independencia en la justicia penal militar en Colombia, lo cual permitirá la 
consulta de autores, sentencias y entrevistas a expertos. Con un enfoque empírico analítico.

La investigación tiene una orientación cualitativa, porque pretende identificar cualidades del tipo de estudio la comparación normativa que se pretende emprender y explicativo en la medida en que se entrará a determinar la adscripción de la justicia penal militar a la rama ejecutiva y la incidencia de los fallos por parte de los operadores judiciales, en los principios de independencia e imparcialidad.

Asimismo es una investigación Jurídica porque su objeto de conocimiento parte del estudio de la norma jurídica, la jurisprudencia y las diferentes doctrinas jurídicas del pensamiento.

\section{Justicia Penal Militar}

Los estudios relacionados con la justicia penal militar colombiana son escasos, por consiguiente son pocos los escritos especializados en materia de las instituciones procesales propias del derecho penal militar colombiano, la indiferencia que se observa es lo que motiva para ingresar a esta área en su naturaleza, estructura y funcionamiento, más aun lo relacionado con los procedimientos establecidos por los actuales Códigos Penales Militares - Leyes 522 de 1999, 1407 de 2010 y 1765 de 2015 los cuales aplican conjuntamente en el actual proceso penal militar, estas últimas incorpora la oralidad y reestructura la justicia penal militar y policial estableciendo requisitos para el desempeño de cargos al interior de la misma jurisdicción; dicha norma solo se está aplicando la parte sustantiva aplicando el principio de favorabilidad .

Esta aplicación simultánea de dos regímenes procesales (Ley 522 de 1999 - Mixto con tendencia acusatoria, Ley 1407 de 2010 - Sistema Penal Oral Acusatorio, Ley 1765 de 2015 - reestructura la J.P.M. y Policial) es el escenario para que desde la academia se determine el concepto de los principios de imparcialidad e independencia por parte de los jueces en el juzgamiento de delitos en el marco de la justicia penal militar adscrita a una línea de mando en el poder ejecutivo del poder público colombiano. 
Este es un país que ha tenido un conflicto interno por décadas, por lo que se hace necesario tener una fuerza pública activa y esa conducta se ve reflejado en la existencia y mantenimiento de una jurisdicción penal militar, por ello es importante blindar a la fuerza pública para darle más credibilidad en sus decisiones judiciales garantizando los principios de Imparcialidad e independencia.

La Corte Constitucional en (Sentencia C-141, 1995 ) (M.P.: Antonio Barrera Carbonell) señala:

La Constitución Política establece de manera expresa e inequívoca la existencia de la Justicia Penal Militar y del respectivo Código Penal Militar, los cuales le dan sustento legítimo al fuero. Sin embargo, es igualmente claro que la Justicia Penal Militar y las normas que la regulan deben sujetarse a los principios de independencia, imparcialidad y objetividad, inherentes al debido proceso y al ejercicio de la función jurisdiccional.

Por ello resulta adecuado analizar la estructura del proceso penal militar y los dos sistemas procesales actualmente vigentes, con herramientas de consulta nacional e internacional existentes para solucionar las dificultades interpretativas que al respecto se suscitan y determinar la efectividad de las disposiciones.

De otra parte, se hace necesario estudiar la pertenencia de la justicia penal militar a la rama ejecutiva, señalando que administra justicia como lo señala nuestra constitución política en su artículo 228 y la Corte Constitucional en (Sentencia C-037, 1996) (M.P.: Vladimiro Naranjo) preciso:

La justicia penal militar no pertenece a la rama judicial del poder público, básicamente por dos razones: Las autoridades de la rama judicial están señaladas expresamente en el Título VIII de la Constitución Política. Hay órganos o funcionarios que por expresa disposición constitucional administran justicia, entre ellos la justicia penal militar, que lo hace por disposición de los artículos 116 y 221 de la Carta, pero por no estar incluidos dentro de los órganos previstos en el Título VIII, no pertenecen a la rama judicial del poder público. 
En segundo lugar, la Corte hace referencia al Auto No. 12 del $1^{\circ}$ de agosto de 1.994 de la misma corporación, M.P. Jorge Arango Mejía, donde se concluyó: "Es verdad que la justicia penal militar, según lo dice el artículo 116 de la Constitución Nacional, administra justicia, pero lo hace de manera restringida, no sólo por los sujetos llamada a juggar, sino por los asuntos de los cuales conoce".

Los estudios especializados que se han realizado en Colombia sobre Justicia Penal Militar, no han tratado a profundidad esta temática, especialmente los relativos a los principios de Imparcialidad e Independencia que orientan y soportan las decisiones judiciales; así como el alcance y la pertenencia de esta jurisdicción a la rama ejecutiva del poder público colombiano. En este aparte se reseñaran los principales estudios que se han desarrollado a nivel nacional e internacional en relación al tema objeto de estudio.

Tabla No. 1: Estado del arte sobre Justicia Militar

\begin{tabular}{|c|c|c|c|c|}
\hline & Autor & Título & Fuente & Resumen \\
\hline 1. & $\begin{array}{l}\text { Jorge Me- } \\
\text { ra Figue- } \\
\text { roa }\end{array}$ & $\begin{array}{l}\text { La Jus- } \\
\text { ticia Penal } \\
\text { Militar en } \\
\text { Chile }\end{array}$ & $\begin{array}{l}\quad \text { Mera } \\
\text { Figueroa, } \\
2000) \\
\quad \text { La Jus- } \\
\text { ticia Penal } \\
\text { Militar en } \\
\text { Chile, Facul- } \\
\text { tad Latinoa- } \\
\text { mericana de } \\
\text { Ciencias Socia- } \\
\text { les } \\
\text { (FLACSO), } \\
\text { p.25-35. }\end{array}$ & $\begin{array}{l}\text { Este libro trata de } \\
\text { señalar que la sociedad } \\
\text { chilena se ha esforzado } \\
\text { desde comienzos de este } \\
\text { siglo, por reformar la } \\
\text { estructura de su sistema } \\
\text { penal, regulando su enfo- } \\
\text { que probatorio y trans- } \\
\text { formándolo a uno con } \\
\text { tendencia acusatoria y } \\
\text { oral, despojando los hábi- } \\
\text { tos escriturales e inquisi- } \\
\text { tivos. } \\
\text { El autor trata de ex- } \\
\text { plorar el por qué la socie- } \\
\text { dad chilena, no se intere- }\end{array}$ \\
\hline
\end{tabular}


El principio de imparcialidad en la justicia militar penal colombiana

\begin{tabular}{|c|c|c|c|c|}
\hline & & & & $\begin{array}{l}\text { só en reformar el código } \\
\text { de } 1926 \text { respecto a la jus- } \\
\text { ticia penal militar en este } \\
\text { país y preferir mantenerla } \\
\text { de forma similar desde su } \\
\text { nacimiento a la vida jurí- } \\
\text { dica. (p.32) }\end{array}$ \\
\hline 2. & $\begin{array}{l}\text { Bordalí } \\
\text { Salaman- } \\
\text { ca, A. }\end{array}$ & $\begin{array}{l}\text { El de- } \\
\text { recho fun- } \\
\text { damental a } \\
\text { un Tribunal } \\
\text { Indepen- } \\
\text { diente e } \\
\text { Imparcial } \\
\text { en el orde- } \\
\text { namiento } \\
\text { jurídico } \\
\text { chileno. }\end{array}$ & $\begin{array}{l}\text { (Bordalí } \\
\text { Salamanca, } \\
\text { 2009) Revis- } \\
\text { ta de Dere- } \\
\text { cho de la } \\
\text { Pontificia } \\
\text { Universidad } \\
\text { Católica de } \\
\text { Valparaiso. } \\
\text { Pag } \\
\text { 263-302 }\end{array}$ & $\begin{array}{l}\text { Se analiza el conteni- } \\
\text { do esencial del derecho a } \\
\text { un tribunal independiente } \\
\text { e imparcial y se estudia la } \\
\text { situación de este derecho } \\
\text { en diferentes jurisdiccio- } \\
\text { nes, entre ellas la militar, } \\
\text { la posición de la CIDH } \\
\text { respecto de la imparciali- } \\
\text { dad e independencia ha } \\
\text { sostenido que los tribuna- } \\
\text { les militares chilenos no } \\
\text { satisfacen los requisitos } \\
\text { de imparcialidad e inde- } \\
\text { pendencia debido a la } \\
\text { ubicación de los órganos } \\
\text { de la justicia militar al } \\
\text { interior de la ramas del } \\
\text { poder público. }\end{array}$ \\
\hline 3. & $\begin{array}{l}\text { Carlos } \\
\text { López } \\
\text { Dawson }\end{array}$ & $\begin{array}{l}\text { Justicia } \\
\text { Militar: } \\
\text { Una nueva } \\
\text { mirada }\end{array}$ & $\begin{array}{l}\text { (López } \\
\text { Dawson, } \\
\text { 2007) } \\
\text { Justicia } \\
\text { Militar: Una } \\
\text { nueva mira- } \\
\text { da Comisión } \\
\text { Chilena de } \\
\text { Derechos Hu- }\end{array}$ & $\begin{array}{l}\text { El autor hace un es- } \\
\text { tudio del proyecto de ley } \\
\text { con fecha } 22 \text { de junio de } \\
2007 \text {, que modifica el Có- } \\
\text { digo de Justicia Militar en } \\
\text { dos aspectos básicos: la } \\
\text { restricción de la compe- } \\
\text { tencia para el juzgamiento } \\
\text { de civiles, por una parte, y }\end{array}$ \\
\hline
\end{tabular}




\begin{tabular}{|c|c|c|c|c|}
\hline & & & $\begin{array}{l}\text { manos, } p, 58- \\
89\end{array}$ & $\begin{array}{l}\text { la derogación de la pena } \\
\text { de muerte que se mantie- } \\
\text { ne hasta la fecha en la } \\
\text { legislación } \\
\text { se.(p.67) }\end{array}$ \\
\hline 4. & $\begin{array}{l}\text { Renato } \\
\text { Astrosa } \\
\text { Sotoma- } \\
\text { yor }\end{array}$ & $\begin{array}{l}\quad \text { Juris- } \\
\text { dicción } \\
\text { penal mili- } \\
\text { tar: estudio } \\
\text { crítico y } \\
\text { comparati- } \\
\text { vo }\end{array}$ & $\begin{array}{l}\text { (Astrosa } \\
\text { Sotomayor, } \\
\text { 1973) } \\
\quad \text { Juris- } \\
\text { dicción pe- } \\
\text { nal militar: } \\
\text { estudio críti- } \\
\text { co y compa- } \\
\text { rativo. Edi- } \\
\text { torial Jurídi- } \\
\text { ca de Chile, } \\
\text { p. } 170-185\end{array}$ & $\begin{array}{l}\text { El libro explora los } \\
\text { estándares internacionales } \\
\text { de derechos humanos que } \\
\text { son aplicados los sistemas } \\
\text { de justicia militar, relacio- } \\
\text { nado con el principio de } \\
\text { la independencia e impar- } \\
\text { cialidad de los tribunales. } \\
\text { La investigación describe, } \\
\text { analiza y compara los } \\
\text { comentarios y la jurispru- } \\
\text { dencia de organismos } \\
\text { internacionales de dere- } \\
\text { chos humanos. El estudio } \\
\text { se enfoca en cuatro sub- } \\
\text { sistemas internacionales y } \\
\text { regionales de protección } \\
\text { de los derechos humanos: } \\
\text { el Comité de Derechos } \\
\text { Humanos del Pacto de } \\
\text { Derechos Civiles y Políti- } \\
\text { cos, la Comisión Africana } \\
\text { de Derechos Humanos y } \\
\text { de los Pueblos, la Corte } \\
\text { Interamericana de Dere- } \\
\text { chos Humanos y el Tri- } \\
\text { bunal Europeo de Dere- } \\
\text { chos Humanos. A partir } \\
\text { del análisis comparativo, }\end{array}$ \\
\hline
\end{tabular}


El principio de imparcialidad en la justicia militar penal colombiana

\begin{tabular}{|l|l|l|}
\hline & & $\begin{array}{l}\text { se definen tres estándares } \\
\text { de independencia e im- } \\
\text { parcialidad aplicable a } \\
\text { tribunales militares, a } \\
\text { saber, la exclusión de } \\
\text { civiles de la justicia mili- } \\
\text { tar, y la definición de ga- } \\
\text { rantías de independencia } \\
\text { e imparcialidad en el fue- } \\
\text { ro militar.(p.176) }\end{array}$ \\
\hline
\end{tabular}

Fuente: Elaboración propia

\section{Justicia}

Siendo la justicia y la imparcialidad dos conceptos ampliamente discutidos a la luz de la filosofía política, se hará mención a las acepciones que más irradian el presente tema, no sin antes resaltar que son conceptos cambiantes con la historia y las diferentes sociedades a la par de las diferentes corrientes filosóficas. Así pues, el marxismo, por ejemplo, concibe la justicia como la idea de liberar a la sociedad de toda explotación; en el socialismo éste concepto gira en torno a la igualdad de derechos y colaboración entre todos los pueblos, y por último en el comunismo se identifica con la ausencia de heterogeneidad social y económica.

Para efectos de la presente investigación, el sentido de justicia pertinente es el jurídico, que en términos de Ponce Esteban (2005, p.212), hace referencia al conjunto de instituciones encargadas de administrar justicia conforme al sistema jurídico.

Para John Rawls, tomando como base el análisis sobre su teoría de la justicia, realizada por José Francisco Caballero (2006, pág. 2), justicia e imparcialidad se equiparan, pues, el mismo denominó a su teoría justicia como: imparcialidad, apoyado en la idea de que solamente a partir de condiciones imparciales se pueden obtener resultados imparciales. Al respecto de la misma señalaba que: El objeto primario de la justicia es la estructura básica de la sociedad, o sea, el modo en que las grandes instituciones sociales distribuyen los derechos y deberes fundamentales y 
determinan la división de las ventajas provenientes de la cooperación social. (pág.5) Debe resaltarse que para Rawls, las grandes instituciones son la constitución política y las principales instituciones económicas y sociales, encargadas de definir los cargos y posiciones, cargas y beneficios, poderes e inmunidades, para todos aquellos que se rigen por ellas. Es decir, su teoría de la justicia gira en torno en la adecuada distribución de dichos elementos, la cual debe hacerse con imparcialidad, dentro de la estructura social respectiva.

Para Habermas, bajo su teoría de la ética discursiva, la justicia se basa en dos pilares: el reconocimiento recíproco de los seres humanos como personas, y el procedimiento para establecer normas válidas. (Ponce Esteban, 2005, p.219), así mismo, dice que la justicia debe depender de la legitimidad política en las instituciones.

\section{Imparcialidad}

Lo que más destaca Aristóteles es que la imparcialidad no es una característica que se desprenda de la ética o la moral sino del saber juzgar bien. Según Aristóteles:

... constituye una condición de la virtud relativa al buen juicio de la razón práctica, una disposición intelectual que facilita la realización de buenos o acertados juicios, por eso la imparcialidad debe situarse en la esfera de la razón práctica y no de la esfera de la ética. La imparcialidad está presente en el momento del juicio, no se deduce o induce de ningún razonamiento, sino que preside de la formulación de juicios y razonamientos; el momento de la imparcialidad en el juicio práctico tiene algo de instantáneo y único, careciendo de carácter discursivo, albergando un carácter intuitivo. Desde la perspectiva de Aristóteles se trata de identificar a quien puede ser capaz de juzgar las cosas de manera imparcial con la sabiduría e inteligencia de vivir bajo un ordenamiento recto. Entonces seria imparcial quien bajo la Ley no está condicionado por pasiones y no hace distinciones en virtud de prejuicios, respetando el equilibrio entre los sujetos. 
El principio de imparcialidad en la justicia militar penal colombiana

El concepto de imparcialidad en Kant se evidencia cuando manifiesta que

... para juzgar se deben tener en cuenta dos conceptos: el juicio y la razón. Se puede sostener la imparcialidad en el juicio cuando se juzga según la ley y se verifica cuando se aplica la ley al caso en concreto. (...) La imparcialidad está conectada con el concepto de ley válida para todos, que coincide con la universabilidad del juicio; la postura imparcial será, pues la que se adecua a la ley contando con que la ley está enfocada con lo universal.

Sobre este concepto en relación con la actividad judicial, Kant considera que

En la resolución del conflicto el juez se encuentra en una situación supra-parte, que le legitima a resolverlo conforme a derecho y como alguien ajeno al pleito, pero esa legitimidad le viene otorgada porque se enfrenta a la solución de la controversia desde la mas pura objetividad, sin que exista ningún interés propio en el pleito y sin estar sometido a influencia o presión de cualquier naturaleza. Lo que legitima al juez a los ojos de las partes es la posición de independencia e imparcialidad desde que actúa, esto es la confianza de que su decisión estará por encima de cualquier condicionante.

Asimismo realiza una clasificación entre imparcialidad subjetiva y objetiva:

La imparcialidad subjetiva alude a la convicción personal del juez en concreto que conoce de un determinado asunto y, de este modo a su falta de prejuicios. Por su parte la imparcialidad objetiva se refiere a si tal juez se encuentra en una situación dotada de garantías bastantes para disipar cualquier duda razonable acerca de su parcialidad. 
Uno de los aspectos que con mayor amplitud resalta Kant es que para que exista imparcialidad objetiva se debe también garantizar la independencia judicial, es decir, que le juez pueda actuar sin intromisiones de los demás poderes estatales.

\section{Jurisdicción Penal Militar}

La Jurisdicción es la capacidad o facultad que tienen los jueces de administrar justicia. Según lo precisa la Constitución Política, la jurisdicción puede ser ejercitado solo por la Corte Suprema de Justicia, la Corte Constitucional, el Consejo de Estado y el Consejo Superior de la Judicatura; sino que también los hacen los órganos que tiene la misión de ejercer la Justicia Penal Militar

Pese a que la Carta Política reconoce la jurisdicción penal militar, esta no forma parte de la rama judicial, así lo ha determinado la Corte Constitucional al expresar que:

Si bien, de acuerdo a nuestra Carta Política "la jurisdicción penal militar" orgánicamente no integra o no forma parte de la rama judicial, sí administra justicia en los términos, naturaleza y características consagradas en el artículo 228 ibídem, esto es, en forma autónoma, independiente y especializada, debiendo en sus actuaciones otorgar preponderancia al derecho sustancial, como se reitera en el artículo 203 del Código Penal Militar.

El mismo artículo 228 define la administración de justicia como función pública a cargo del Estado, garantizando a toda persona, en su artículo 229 ibídem el derecho para acceder a la misma, lo cual se extiende a la justicia penal militar. Así mismo el mandato constitucional contenido en el artículo 230 C. P., que reitera el que los jueces en sus providencias están sometidos al imperio de la ley y que la equidad, la jurisprudencia, los principios generales del derecho y la doctrina son criterios auxiliares de la actividad judicial, es aplicable también a la justicia penal militar que como se señaló administra justicia aunque orgánicamente no integre la rama judicial del poder público; mandato que se transcribe en el artículo 201 del Código Penal Militar. 
Por último, la justicia penal militar como quiera que como se señaló, está sometida al imperio de la ley entendida esta en su sentido material, también está sujeta en su actividad judicial a la estricta observancia de los preceptos constitucionales y en especial a los contenidos en los artículos 28 a 35 garantizando los derechos fundamentales respectivos, tales como, el debido proceso, la libertad, la doble instancia, reconocimiento de la dignidad humana, no reformatio in pejus etc., que se incorporan expresamente al Código Penal Militar en los artículos 196 a 200 y 207. (Sentencia C-1149, 2001)

Ahora bien, lo más común dentro de la sociedad colombiana y en general en cualquier ordenamiento jurídico son los problemas entre particulares con otros particulares, y entre los particulares y el estado, y para resolver esos conflictos se requiere de una administración de justicia, para que aplique la normatividad valida y los principios del derecho dándole tranquilidad a la sociedad y de este modo solucionar los conflictos presentados, y para esto, el Estado dentro de sus funciones en la rama judicial, tiene unas jurisdicciones encargadas de administrar justicia y poder así resolver cualquier problema. El título VIII de la carta política colombiana contiene los capítulos, señalando que las jurisdicciones son: La ordinaria, contencioso Administrativo, La constitucional y las de los territorios indígenas, esto quiere decir que los problemas más comunes, los presentados con mayor frecuencia son resueltos por estas jurisdicciones dependiendo del tipo del problema en que se encuentre.

Adicionalmente, e incluyente de la Rama Ejecutiva, se encuentra la jurisdicción Penal Militar, ya que las armas (FFMM), son controladas por el mismo ejecutivo, El ejecutivo es el encargado de controlar la fuerza del estado decía Maquiavelo, por esta razón esta jurisdicción hace parte de la Rama Ejecutiva, y a la vez nos encontramos con que los problemas que son presentados bajo esta administración, no son comunes y rara vez salen a la vida público, puesto que tienen un fuero especial y su estudio por parte de la Jurisprudencia y la Doctrina colombiana no tiene la misma experiencia que encontramos con tanta amplitud en las jurisdicciones pertenecientes a la Rama Judicial.

En este orden de ideas, podemos decir que la Jurisdicción Penal Militar como: "el punitivo peculiar de la milicia contenido por lo común en 
el Código de Justicia Penal Militar. Está constituido por las normas y principios que establecen los delitos por infracción de los deberes del servicio, por violar la disciplina del ejecito, por desobediencia o rebeldía de las fuerzas armadas ante los poderes legítimos del Estado y otros inherentes a la condición militar, con las consiguientes penas, de proverbial severidad" (Cabanellas, 1953, pág. 655) es decir que es la parte del derecho encargada de estudiar y aplicar la violación al ordenamiento penal militar, la cual contiene unas sanciones, en donde los delitos solo pueden ser cometidos por militares.

La sentencia C-878 de 2000 de la Corte Constitucional Colombiana refiriéndose a la jurisdicción penal militar diciendo que "Ha sido el propio Constituyente tal como lo ha reconocido la jurisprudencia de esta Corporación, el que limitó el alcance del fuero militar y la aplicación excepcional de la jurisdicción penal militar, al señalar los elementos estructurales de éste, pues expresamente señaló que sólo podrán ser juzgados por la jurisdicción penal militar, los miembros activos de la fuerza pública, entiéndase fuerza militar y policía nacional, cuando éstos comentan un delito relacionado con el servicio mismo. Así, se ha dicho que son dos los elementos que deben estar presentes para que opere la competencia de las Cortes marciales o tribunales militares. El primero, de carácter subjetivo, pertenecer a la institución castrense y ser miembro activo de ella, el segundo, de carácter funcional, por cuanto el delito cometido debe tener relación con el servicio".

Esto quiere decir que le agrega dos componentes al concepto de jurisdicción penal militar, que al mismo tiempo se encuentran estipulados en la ley 1407 de 2010 en sus artículos 1 y 2, son la calidad del sujeto, pues este debe de pertenecer a las fuerzas públicas, y que la conducta delictiva sea cometida encontrándose en servicio y en relación al mismo, por lo que no cumpliendo con estos requisitos la jurisdicción encargada de administrar justicia seria la penal ordinaria.

\section{a) Destinatarios de la Justicia Penal Militar}

La justicia penal miliar encuentra su fundamento expreso en el fuero penal militar que brinda a la fuerza pública unos parámetros para ser investigados, juzgados y sancionados, esta restricción está reconocida por 
la Constitución Política de Colombia en el artículo 221, el cual dispone que:

De los delitos cometidos por los miembros de la fuerza pública en servicio activo, y en relación con el mismo servicio, conocerán las Cortes Marciales o Tribunales Militares, con arreglo a las prescripciones del Código Penal Militar. Tales Cortes o Tribunales estarán integrados por miembros de la Fuerza Pública en servicio activo o en retiro (Constitución Política de Colombia, 1991).

De esta disposición se desprende uno de los aspectos nucleares de la justicia penal militar, esto es, a quienes se aplican sus disposiciones. Como se reseñó previamente el derecho penal militar aplica para la fuerza pública, la cual de conformidad con el artículo 216 de la Constitución Política está conformada por las Fuerzas Militares y por la Policía Nacional.

\section{b) Proceso Penal Militar}

El proceso penal militar se encuentra regulado en la actualidad por dos disposiciones normativas, a saber, la Ley 522 de 1999 y la Ley 1407 de 2010; Estas normas recogen los aspectos sustanciales y procedimentales de la justicia penal militar; pues se ocupan de determinar aquellos comportamientos que se consideran ilícitos para esta rama del derecho y consecuentemente determinan el procedimiento sancionatorio para el personal que incurra en esta clase de comportamientos. Las normas en cita se están aplicando de manera simultánea en la actualidad, la Ley 522 de 1999 de manera principal y la Ley 1407 de 2010 de manera excepcional, tomando la parte sustantiva de la misma en virtud de la aplicación del principio de favorabilidad. De conformidad con la Ley 522 de 1999 se desarrolla a través de las siguientes fases: 


\section{Fase investigativa}

En esta estapa, el juez penal militar debe investigar los hechos que apunten a responsabilizar al procesado y aquellos que la atenúen o que la extingan. - Hay práctica de pruebas -

\section{Fase de calificación}

En esta etapa el funcionario debe proferir resolución de acusación o disponer la cesación del procedimiento.

\section{Fase de juicio}

Intervienen cada uno de los sujetos procesales y finalizada la audiencia, el juez dispondrá de 8 días para dictar sentencia. - Hay práctica de pruebas Corte Marcial.

Fuente: Elaboración Propia. (Petro Gónzalez, Henao Toro, \& Marín Pinto, 2013, págs. 40-41)

\section{Marco jurídico}

La justicia penal militar ha sido regulada por varias normativas que deben ser precisadas. Una de las primeras normas que se encargó de sistematizar la justicia penal militar fue el (Decreto 2550, 1988) - entra en vigencia el 12 de junio de 1989 -, el cual fue expedido en ejercicio de la facultades extraordinarias conferidas al Presidente de la República por la Ley 53 de 1987; y en la que se fusionaban dos funciones que fueron separadas, esto es, las funciones de comando y la función jurisdiccional.

En vigencia del citado decreto los miembros de las Fuerzas Militares y de la Policía Nacional eran investigados y juzgados por los comandantes de los Batallones, Brigadas y Departamentos de Policía y no por jueces especializados, lo que generaba cuestionamiento de los fallos impartidos.

En 1999 el Congreso de la República expidió la Ley 522- entra en vigencia el 13 de agosto de 2000 - con la cual se deroga el antiguo Código Penal Militar; se introdujo un elemento novedoso con la separación las funciones de comando y jurisdiccionales y la consecuente creación de los jueces penales militares. El sistema procesal introducido por esta disposi- 
ción, es un sistema mixto en el que el juez impulsa el proceso, la actividad probatoria, pero su fallo es de manera oral realizado por una Corte Marcial en cabeza de un juez de conocimiento penal militar, tal como lo señala el art 559 de la Ley 522 de 1999.

Posteriormente se expide la Ley 1407 de 2010 - entra en vigencia el 17 de agosto de 2010-, en la que se conserva el principio de separación de las funciones directivas de las puramente jurisdiccionales y se introduce una reforma sustancial al procedimiento penal militar, el cual deja de ser Mixto, con tendencia acusatoria para convertirse en un sistema acusatorio - Dispositivo - donde, como ocurre con el proceso penal ordinario, son las partes las encargadas de demostrar ante el juez competente los hechos que soportan sus peticiones tanto absolutorias como condenatorias.

\section{Marco contextual}

Aunque el conflicto armado interno en el que se encuentra sumido el Estado Colombiano es una verdad histórica, el reconocimiento institucional de esta situación solo se produce con la expedición de la (Ley 1448 , 2011). El inciso primero del artículo 3 de este cuerpo normativo establece que se consideran víctimas aquellas personas que hayan recibido daños producto de violaciones a los Derechos Humanos y Derecho Internacional Humanitario en el marco del conflicto armado interno.

Esta situación de conflicto demanda de la fuerza pública incesantes esfuerzos destinados a desarrollar estrategias militares para cumplir con el deber constitucional establecido en el artículo 217 superior de velar por defensa de la soberanía, la independencia, la integridad del territorio nacional y del orden constitucional. Lo anterior implica que será cada vez más frecuente la aplicación de la justicia penal militar y el estudio de sus instituciones deberá tornarse en un elemento de obligatorio para funcionarios, académicos, estudiantes, y litigantes.

El derecho penal militar colombiano no es un tema de estudio frecuente por parte de los académicos del derecho. Sin embargo la expedición de la Ley 1407 de 2010 y su aplicación coetánea con la Ley 522 de 1999, exige que se aborde el análisis de la estructura del proceso penal 
militar colombiano en cada uno de los regímenes procesales indicados; que se haga claridad frente aquellas disposiciones vigentes y que se contrasten en cada una de las etapas e instituciones procesales a fin de establecer, al menos de manera palmaria, el rol de cada uno de las parte dentro del proceso.

Este estudio constituiría una herramienta de utilidad jurídica eminentemente práctica que aportará recursos y ámbitos de reflexión sobre los problemas y contradicciones en la aplicación de los dos universos normativos citados.

\section{Conclusiones}

Como resultados de la presente investigación se tiene que en desarrollo de la reforma constitucional introducida por el Acto Legislativo 03 de 2002 la cual reformó los artículos 116, 250 y 251 de la Constitución Política, se modificó la estructura básica del proceso penal al interior de la justicia penal militar, el cual pasaría de un modelo mixto con tendencia acusatoria inquisitiva, a un sistema procesal penal con tendencia acusatoria, que pretende privilegiar la garantía de los derecho fundamentales del inculpado para la consecusión de la verdad, la realización efectiva de la justicia y los derechos de las víctimas.

La finalidad de este proceso con tendencia acusatoria ha sido regulado y desarrollado para que se cumplan tres etapas: indagación, investigación y juicio, caracterizado este por un juicio oral, público, concentrado y contradictorio, en donde se garantice por parte de operador jurídico la aplicación de los principio de imparcialidad e independencia, teniendo presente que la imparcialidad del juez es un elemento indispensable para asegurar el problema político - práctico de la separación de poderes.

Tal como lo señala Loewenstein; "la independencia de las funciones que le sean asignadas al operador judicial y su libertad frente a todo tipo de poder, constituye la piedra final por la construcción de un Estado democrático constitucional de derecho". (1996)

De esta manera se puede inferir que con la implementación de esta figura acusatoria al interior de la justicia militar los operadores judi- 
El principio de imparcialidad en la justicia militar penal colombiana

ciales al administrar justica gozan de una serie de principios constitucionales que garantizaran el debido proceso.

\section{Fuentes de información}

Aguiló Regla, J. (2009). Imparcialidad y concepciones de derecho. Revista Jurídicas 6-2, 27 - 44.

Agudo Ruiz, A., (2009).Nota sobre la jurisdicción militar en C. J. 12. 35.18 Revista General de Derecho Romano, ISSN-e 1697-3046, Nº 12

Aguiló, J. (1996). Independencia e imparcialidad de los jueces y argumentación jurídica.

http:// www.sitios.scjn.gob.mx/instituto/sites/default/files/archivos/independencia-eimparcialidad-de-los-jueces.pdf.

Amnistía Internacional. (2004). México mujeres e injusticia militar. Amnistía Internacional, 22.

Andreu-Guzmán, F. (2011). Tribunales militares y graves violaciones de derechos humanos. Bogotá: Comisión Colombiana de Juristas.

Astrosa Sotomayor, R. (1973). Jurisdicción penal militar: estudio crítico y comparativo. Editorial Jurídica de Chile, p. 170-185

Ayala Corao, C. (2009). La independencia de la justicia y los procesos constituyentes en la región andina. Chile: Red Estudios Constitucionales.

Balarenzo Revilla, J. L., \& Belaúnde de Cárdenas, A. (2009). ¿Si, Señor Presidente? Mecanismos de selección de los jueces militares en Perú. Revista mensual de jurisprudencia, 165.

Bardelli Lartirigoyen, J. B. (15 de Junio de 2005). Independencia e imparcialidad en la Justicia Militar a propósito de la reciente sentencia del TC. El peruano.

Berrios, O.,(2013). Enfoques epistemológicos que orientan la investigación de 4to nivel. Disponible En: http://www.saber.ula.ve/bitstream/123456789/31329/1/articulo4.pdf Acceso 2 de diciembre de 2013.

Bordalí Salamanca, A. (2009). El derecho fundamental a un Tribunal independiente e imparcial en el ordenamiento jurídico chileno. , . En Revista de Derecho de la Pontificia Universidad Católica de Valparaiso (págs. 263 - 302). Pontificia Universidad Católica de Valparaiso.

Cabanellas, G. (1953). Diccionario de Derecho Usual. Editorial Arayú. 
Chaparro, J. C. (2010). Fuero y justicia penal militar en Colombia: debates y controversias. En Revista Memoria y Sociedad. ISSN-e 0122-5197, Vol. 14, No. 29 (págs. 71-90).

Blanco Valdés, Roberto L., (1996). La configuración del concepto de Constitución en las experiencias revolucionarias francesas y norteamericanas. Barcelona, Institut de Ciéncies Politiques Sociales. Página 11.

Cabarcas Maciá, G. (2011). Militares, política y derecho sobre los silencios del constituyente de 1991. Colombia: Universidad de los Andes.

Calderón Cerezo, Ángel (2012) Delimitación Constitucional de la Jurisdicción Militar, La ley penal: Revista de derecho penal, procesal y penitenciario, ISSN 1697-5758, No. 98-99 pág. 2

Camelo José, A. (2006). Evolución de las Cortes Marciales. Revista Prolegómenos. Derechos y Valores de la Facultad de Derecho, ISSN-e 0121-182X, Vol. 9, No. 18, 2006 , págs.227-236

Castro, G. F., \& Bermeo Lara, D. (2008). Justicia Militar, Códigos Disciplinarios y Reglamentos Generales Disciplinarios. Buenos Aires: RESDAL.

Contreras , P. (2011). Independencia e imparcialidad en sistemas de justicia militar: estándares internacionales comparados. Estudios Constitucionales, Año 9, No. 2, 191 - 248.

Constitución Política de Colombia (1991).

Decreto 2550, Nuevo Código Penal Militar (Presidente de la República 1988).

Defensoría del Pueblo Perú. (2003). ¿Quién ju₹ga que? justicia militar vs. justicia ordinaria. Lima : Defensoría del Pueblo.

Devis Echandía, H. (1993). Compendio de derecho procesal . Bogotá: Biblioteca Jurídica Diké.

Díaz García, I. (2009). Derechos fundamentales y decisión judicial. Algunos criterios para la mejor aplicación del Derecho Penal. Getafe: Universidad Carlos III de Madrid.

Díaz Tolosa, R. (2007). Reforma de la Justicia Militar chilena a la luz de las consideraciones del fallo Palamara. Pontificia Universidad Católica de Chile. Facultad de Derecho Revista Chilena de Derecho, vol. 34 No 1, pp. 139 - 151

Doing Díaz, Y. (2002). La jurisdicción militar a la luz de las garantías de la jurisdicción. La reforma del derecho penal millitar, 27 - 64.

Hart, H. L. (1992). El concepto de Derecho . Buenos aires : Abeledo Perrot (Traducción) . 
Ley 1448 , Ley de víctimas (Congreso de la República 2011).

Ley 522, Actual Código Penal Militar Colombiano. (Congreso Nacional de la República 1999).

López Dawson, C. (2007). Justicia Militar: Una nueva mirada Comisión Chilena de Derechos Humanos.

Mera Figueroa, J. (2000). La Justicia Penal Militar en Chile, Facultad Latinoamericana de Ciencias Sociales (FLACSO).

Petro Gónzalez, I. R., Henao Toro, C. A., \& Marín Pinto, F. A. (2013). La Justicia Penal Militar colombiana y los principios procesales constitucionales de independencia e imparcialidad, después de la separación de la función de jurisdicción con la función de comando. Pereira: Universidad Libre Seccional Pereira.

Sentencia C-037 (Corte Constitucional 1996).

Sentencia C-1149 (Corte Constitucional 2001).

Sentencia C-141 (Corte Constitucional 29 de marzo de 1995 ). 